\title{
O impacto das fake news e a sua influência na automedicação na COVID-19
}

\author{
The impact of fake news and its influence on self-medication in COVID 19 \\ Leila Corrêa Bueno Miguel $^{1 *} \bullet$, Ciro José Sousa de Carvalho ${ }^{2}$ \\ ${ }^{1}$ Graduanda em Farmácia da Faculdade de Palmas, Palmas, Tocantins, Brasil. ${ }^{2}$ Professor Adjunto, Faculdade de Palmas, Palmas, \\ Tocantins, Brasil. *Autor para correspondência. E-mail: Leilafacul2@gmail.com
}

\begin{abstract}
Resumo: Introdução: Desde o final de 2019, com a emergência da crise global gerada pelo SARS-CoV-2, a porcentagem da produção e consumo global de notícias e informações sobre o assunto aumentou consideravelmente, com o SARS-CoV-2 a ocupar a maior parte do espaço nos meios de comunicação social. Os objetivos deste trabalho são a análise do impacto causado por notícias falsas, relacionadas com o uso de drogas e outros meios como uma tentativa de prevenir ou curar a doença coronavírus. 2. Revisão: Trata-se de um estudo de natureza descritiva, utilizando como método a revisão bibliográfica, sobre impacto das fake News e a influência na automedicação na covid 19, nas seguintes bases de dados: SciELO, Lilacs e Pubmed, utilizou-se como critérios de inclusão, artigos científicos originais, com palavras-chave pandemia, coronavírus, noticia falsa, automedicação, covid-19, infodemia. 3. Discussão: Infodemia, o mesmo que, o excesso de informação sobre o mesmo tópico, em especial o coronavírus, causou mal-entendidos e uma desorientação por parte das pessoas, que perdem ou minimizam a capacidade de reconhecer as fontes e conteúdos confiáveis. Os resultados obtidos indicam que uma grande parte da comunidade caiu na disseminação de informações falsas mesmo antes da entrada do vírus no país. 4. Considerações Finais: Nesse sentido, pesquisas futuras devem se concentrar em intervenções educacionais preventivas que forneçam aos usuários as habilidades de que precisam para acessar informações baseadas em evidências e rejeitar falsidades. Medidas necessárias para controlar qualquer infodêmico. Nesse sentido, esse tipo de análise pode ajudar as autoridades de saúde a se manterem atualizadas sobre como os usuários de redes sociais compartilham informações.
\end{abstract}

Palavras-chave: pandemia, coronavírus, noticia falsa, automedicação, covid-19, infodemia.

\begin{abstract}
Introduction: Since the end of 2019, with the emergence of the global crisis generated by SARS$\mathrm{CoV}-2$, the percentage of global production and consumption of news and information on the subject has increased considerably, with SARS-CoV-2 occupying the largest part of the space in the media. The objectives of this work are to analyze the impact caused by false news, related to the use of drugs and other means as an attempt to prevent or cure coronavirus disease. 2. Review: This is a descriptive study, using the bibliographic review as a method, on the impact of fake news and the influence on selfmedication in covid 19, in the following databases: SciELO, Lilacs and Pubmed. as inclusion criteria, original scientific articles, with keywords pandemic, coronavirus, false news, self-medication, covid-19, infodemia. 3. Discussion: Infodemia, the same as, the excess of information on the same topic, especially the coronavirus, caused misunderstandings and a disorientation on the part of people, who lose or minimize the ability to recognize reliable sources and content. The results obtained indicate that a large part of the community fell in the spread of false information even before the virus entered the country. 4 . Final Considerations: In this sense, future research should focus on preventive educational interventions that provide users with the skills they need to access evidence-based information and to reject falsehoods. Necessary measures to control any infodemic. In this sense, this type of analysis can help health authorities to keep up to date on how social network users share information.
\end{abstract}

Keywords: pandemic, coronavirus, fake news, self-medication, covid-19, infodemic.

\section{Introdução}

A Organização Mundial de Saúde, através da Organização Pan-Americana de Saúde (OPAS), descreveu um relatório sobre infodemia (aumento significativo do volume de informação) relativo à COVID-19. Cita também que a desinformação pode ser entendida como informação falsa ou imprecisa. A OMS adverte que as falsas notícias tornam difícil o estabelecimento de fontes adequadas, promovem um clima de ansiedade e depressão entre as pessoas e podem afetar a tomada de decisões (OPAS, 2020)

Pulido et al. (2020) relatam que o advento da Internet e das redes sociais facilitou inegavelmente a circulação e o alcance da informação, abrindo possibilidades aos utilizadores de aceder, interagir e produzir 
conteúdo, esta situação levou a uma democratização da relação entre o conhecimento e os cidadãos. Contudo, as redes sociais e os sítios em linha tornaram-se também as principais plataformas de divulgação de informações falsas e enganosas, permitindo já uma partilha rápida e em grande escala. De facto, a presença de notícias falsas encontradas e distribuídas em ambientes on-line está a aumentar ao longo dos anos.

O Ministério da Saúde (MS) brasileiro, no seu website, ofereceu um número para as pessoas denunciarem quaisquer suspeitas de notícias falsas, através da WhatsApp. O site destaca-se como "Saúde sem Notícias Falsas" e já tem vários alertas de notícias falsas relacionadas com a covid, títulos como: "Vacina contra a gripe aumenta o risco de adoecer de coronavírus", "Café previne coronavírus", "Medicina para COVID-19", são exemplos de algumas notícias falsas que circulam através de redes sociais e outros sites (Brasil, 2020).

\section{Revisão}

Trata-se de um estudo de natureza descritiva, utilizando como método a revisão bibliográfica, O presente artigo é uma revisão bibliográfica que teve como objetivo buscar artigos que exemplificassem e descrevessem impacto das fake News e a influência na automedicação na covid 19. nas seguintes bases de dados: SciELO, Lilacs e Pubmed, a análise iniciou-se com a leitura dos títulos dos estudos. No segundo momento, foram lidos os resumos e selecionados como critérios de inclusão, artigos científicos originais, aqueles que tinham como palavras-chave pandemia, coronavírus, noticia falsa, automedicação, covid-19, infodemia. Por fim, foi realizada a leitura dos textos selecionados pelos critérios de inclusão e analisados de acordo com a proposta do estudo.

Netto et al. (2020) A infecção com SRA-CoV-2, o vírus que causa a Covid-19, pode causar doença ligeira a grave e, em alguns casos, pode levar à morte. Os principais sintomas incluem geralmente febre, tosse e dificuldade em respirar, mas algumas pessoas não têm quaisquer sintomas.

Sousa Júnior e Raasch (2020) descrevem que a respeito ao novo Coronavírus, a velocidade de transmissão do Fake News tem vindo a aumentar cada vez mais nas redes da Internet, e esta velocidade pode ser considerada maior do que a propagação do próprio vírus. Como um dos principais motores desta falsa notícia, podemos mencionar as redes sociais, contribuindo para a disseminação excessiva destas distorções.

Batista Júnior et al. (2020) relatam que a infodemia pode ser considerada uma das consequências de conduzir a interação do ciberespaço devido ao isolamento. Uma das suas características é a disseminação e troca de informações que afetam diretamente a luta contra a pandemia, incluindo a busca desenfreada de medicamentos e alimentos que teoricamente se diz serem capazes de curar ou prevenir a COVID-19. Para além da falta de produtos capazes de a curar ou prevenir, os infodemia aumentam o risco de contaminação entre as pessoas, encorajando-as a procurar uma cura ou proteção.

A Hidroxicloroquina e a sua predecessora cloroquina são reconhecidas como antimaláricas e para o tratamento de doenças autoimunes, tais como o Lúpus. A Ivermectina é um antiparasitário e antihelmíntico, tendo ambos demonstrado atividade antiviral contra o vírus VID-19, SARS-CoV A associação com Azitromicina, não se destinava à erradicação viral, mas à prevenção da superinfecção bacteriana em certos pacientes (Scolari, 2020).

Erku et al. (2020) descreve que a busca da droga mágica sem garantias de segurança adequadas já se tornou uma fonte de desinformação relacionada com a droga, causando confusão e pânico público. Um exemplo clássico são os recentes anúncios mediáticos de que a Hidroxicloroquina e a cloroquina são a cura potencial para a COVID-19, levando a uma utilização indevida pelo público, o que também resultou numa escassez substancial que afeta os pacientes com artrite ou lúpus. Além disso, as pessoas em muitos países estão a ser induzidas a tomar "curas" não comprovadas e por vezes venenosas para a COVID-19, incluindo o consumo de metanol, cocaína, clorofórmio e éter ("lolo"), exposição solar, e mitos generalizados de redes sociais sobre o uso de ibuprofeno, na próxeno, azitromicina, Ivermectina, vitaminas $\mathrm{C}$ e $\mathrm{D}$, ou um banho quente.

Deduzimos que por parecerem menos "prejudiciais" e mais conhecidos, tanto o antibiótico como o antiparasitário seriam mais aceitáveis de tomar, e também, mais fáceis de adquirir, principalmente, o antiparasitário que não necessita da aviação de prescrição e pode ser comprado livremente em qualquer farmácia.

Arrais et al. (1997) relatam automedicação é uma prática comum vivida pelas civilizações de todos os tempos, definida pela Organização Mundial de Saúde como a "seleção e utilização de medicamentos pelo utilizador para o tratamento de doenças ou sintomas reconhecíveis pelo utilizador". Neste sentido, faz parte das atividades de autocuidado da saúde, assim como os cuidados de higiene, nutrição, estilo de vida, e a influência de fatores socioeconómicos e ambientais. 
No entanto, a utilização generalizada de medicamentos sem orientação médica, acompanhada por uma falta de conhecimento dos potenciais danos para a saúde, são exemplos de intoxicação humana causada por tais práticas. Assim, o uso indiscriminado de medicamentos tornou-se um grande problema de saúde pública a nível mundial (Domingues et al., 2017).

\section{Discussão}

Domingues et al. (2017) relata infodemia, a mesma que, o excesso de informação sobre o mesmo tópico, o especial o coronavírus, causou mal-entendidos e uma desorientação por parte das pessoas, que perdem ou minimizam a capacidade de reconhecer as fontes e conteúdos confiáveis. Com isso, são propensos ao aceitar como verdade aqueles que correspondem aos seus valores ou crenças. Sousa Júnior e Raasch (2020) descreve que é também preocupante dizer que são falsas notícias, pregando também a difusão de informação correta, de modo a trazer mais conhecimento à população, promovendo a educação para a saúde. Algumas das notícias falsas estão listadas no website do Ministério da Saúde e os seus respectivos esclarecimentos, "Cura para Hidroxicloroquina e cloroquina ou coronavírus" Segundo o Ministério da Saúde, não existem provas científicas de qualquer tipo de bebida, alimento, medicamento ou vacina para a COVID-19, estão a ser desenvolvidos estudos no mundo doméstico, mas ainda não há conclusões sobre estes estudos.

\section{Considerações finais}

Concomitante aos impactos causados pela exposição na mídia que a nova pandemia do coronavírus tem causado na população por meio de notícias falsas, surge a necessidade de órgãos governamentais se associarem aos diversos meios de comunicação para desenvolver melhores estratégias de combate à disseminação desenfreada de conteúdos questionáveis, além disso manter a população informada de forma segura, tendo em vista a implementação de ações de controle da disseminação do vírus. É de fundamental importância que o destinatário da informação certifique sua fonte, observe os discursos das autoridades governamentais e, se possível, consulte o site oficial do Ministério da Saúde, se houver algum conteúdo que corresponda às notícias recebidas. No entanto, com o desenvolvimento da produção intelectual sobre assuntos referente a pandemia da COVID-19, espera-se que esta discussão possa contribuir para o desenvolvimento de outras pesquisas nesta área, uma vez que as notícias falsas não param no cenário global da saúde.

Sabemos que a internet democratizou a forma como os cidadãos acessam, produzem e interagem com os conteúdos. No entanto, o avanço dessa democratização requer que os usuários não apenas tenham acesso ao conhecimento científico, mas também tenham as habilidades para avaliar criticamente as informações e separar conteúdos válidos de falsidades. Nesse sentido, pesquisas futuras devem se concentrar em intervenções educacionais preventivas que forneçam aos usuários as habilidades de que precisam para acessar informações baseadas em evidências e rejeitar falsidades. Medidas necessárias para controlar qualquer infodêmico. Nesse sentido, esse tipo de análise pode ajudar as autoridades de saúde a se manterem atualizadas sobre como os usuários de redes sociais compartilham informações.

\section{Referências}

Arrais, P. S. D., Coelho, H. L. L., Batista, M. D. C. D., Carvalho, M. L., Righi, R. E., \& Arnau, J. M. 1997. Perfil da automedicação no Brasil. Revista de Saúde Pública, 31, 71-77.

Domingues, P. H. F., Galvão, T. F., Andrade, K. R. C. D., Araújo, P. C., Silva, M. T., \& Pereira, M. G. 2017. Prevalência e fatores associados à automedicação em adultos no Distrito Federal: estudo transversal de base populacional. Epidemiologia e Serviços de Saúde, 26, 319-330.

Erku, D. A., Belachew, S., Abrha, S., Sinnollareddy, M., Thomas, J., Steadmon, K., \& Tesfaye, W. H. 2021. Quando o medo e a desinformação se tornam virais: o papel dos farmacêuticos em impedir a desinformação de medicamentos durante a 'infodemia' em torno do COVID-19. Research in Social and Administrative Pharmacy, 28(3822), 1551-7411.

Batista Júnior, E. D. S., Medeiros, B. P., Rocha, H. R. D., \& Goldoni, L. R. F. 2020. Observatório Militar. Vetores cibernéticos da pandemia de Covid-19. Disponível em: http://ompv.eceme.eb.mil.br/images/dqbrn/covid/covid-19_analise-7.pdf. Acesso em: 20 set. 2020.

Sousa Junior, J. H. D., \& Raasch, M. 2020. Da Desinformação ao Caos: uma análise das fake news frente à pandemia do Coronavírus (COVID-19) no Brasil. Cadernos de Prospecção, 13(2), 331-346. 
Brasil, Ministério da saúde. 2020. Saúdes em fakenews. Disponível em: https://www.saude.gov.br/fakenews?readmore_limit=200\&show_subcategory_content=-1\&filtersearch=vacina \&limitstart $=0$. Acesso em: 1 out. 2020.

Netto, A. R. Z., Vivan, J. B., Costa, K. C., Pegoretti, M. L., Piccolo, F., \& Maeyama, M. A. 2020. Uma análise das recomendações governamentais brasileiras no enfrentamento da pandemia da Covid-19 a partir das evidências disponíveis. Brazilian Journal of Health Review, 3(3), 4735-4759.

Organização Pan-americana de Saúde [OPAS]. Entenda a infodemia e a desinformação na luta contra a covid19. Disponível em: https://iris.paho.org/bitstream/handle/10665.2/52054/Factsheetinfodemic_por.pdf?sequence=14. Acesso em: 15 set. 2020.

Pulido, C. M., Carballido, B. V., Sama, G. R., \& Gomez, A. 2020. Infodêmico do COVID-19: mais retuite para informações baseadas na ciência sobre coronavírus do que para informações falsas. Infodêmico do COVID-19. International Sociology, 35(4), 377-392.

Scolari, M. J. 2020. Redescubriendo viejos conocidos: el posible papel de la hidroxicloroquina, cloroquina, ivermectina y teicoplanina en el tratamiento del COVID-19. Revista de la OFIL, 30(2), 127-130.

\section{Minicurrículo}

Leila Corrêa Bueno Miguel. Graduanda no curso de Farmácia da Faculdade Fapal. Palmas, Tocantins (TO), Brasil.

Ciro José Sousa de Carvalho. Graduado em Medicina Veterinária pela Universidade Federal do Piauí (UFPI) em 2009, Mestre em Ciência Animal com ênfase em toxicologia pela Universidade Federal do Piauí (UFPI) com participação em Programa de Cooperação Acadêmica (PROCAD) pela Universidade Federal de Minas Gerais (UFMG) -2012 e Doutorado em Ciência Animal com ênfase em Diagnóstico precoce de metástases em câncer de mama pela Universidade Federal do Piauí (UFPI) em 2016. Tem experiência em Docência no Ensino Superior nas áreas: Patologia Geral, Pesquisa Clínica, Anatomia Humana, Anatomia Comparada, Epidemiologia e Saúde Pública, Imunologia, Imunopatologia e Fisiologia aplicada.

Como citar: Miguel, L.C.B., \& Carvalho, C.J.S. 2021. O impacto das fake news e a sua influência na automedicação na COVID 19, 5, 145 . DOI: https://dx.doi.org/10.31533/pubsaude5.a145

Recebido: 17 mar. 2021.

Revisado e aceito: 25 mar. 2021.

Conflito de interesse: os autores declaram, em relação aos produtos e companhias descritos nesse artigo, não ter interesses associativos, comerciais, de propriedade ou financeiros que representem conflito de interesse.

Licenciamento: Este artigo é publicado na modalidade Acesso Aberto sob a licença Creative Commons Atribuição 4.0 (CC-BY 4.0). 